\title{
Elastic Strain Energy Control of the Precipitate Free Zone around Primary Carbides in Nickel Base Alloy 725
}

\author{
M. Song ${ }^{\mathrm{a}, *}$, J. F. Wen ${ }^{\mathrm{b}, \mathrm{c}}$, Z. Jiao ${ }^{\mathrm{a}}$, G.S. Was ${ }^{\mathrm{a}}$
}

${ }^{\mathrm{a} N u c l e a r}$ Engineering and Radiological Sciences Department, University of Michigan, Ann

Arbor, MI 48109, USA

bshool of Mechanical and Power Engineering, East China University of Science and Technology, Shanghai 200237, PR China

${ }^{\mathrm{C}}$ Department of Materials Science and Engineering, Texas A\&M University, College Station, TX 77843, USA

*Corresponding author: M. Song, meowsong@umich.edu

\begin{abstract}
Precipitate free zones (PFZs) are commonly believed to be controlled by either vacancy or solute depletion around sinks. This study shows thatthe PFZaround primary carbides (Nb, Ti)Cis also influenced by stress field in alloy 725, which is a nickel base alloy hardened by $\gamma^{\prime \prime}$ precipitates. Finite element simulation suggests that the interaction energy between the local stress induced by primary carbides and the transformation strain of $\gamma^{\prime \prime}$ causes a bias in their nucleation. These observations show that in addition to diffusion, internal stress can significantly influence the nucleation of precipitates around sinks.
\end{abstract}

Keywords:Alloy 725; microstructure; precipitate free zones (PFZs); stress; finite element (FE); 


\section{Introduction}

Precipitation hardening is a principalmechanism to enhance the mechanical properties of many alloy systems, e.g., aluminum alloys [1-3], magnesium alloys[4], copper alloys[5, 6], and nickel based alloys[7, 8].However, the nucleation process is sensitive to pre-existing defect sinks such as grain boundaries (GBs), dislocations and phase boundaries, giving rise to an inhomogeneous spatial distribution of precipitates. A noticeable feature of many age hardened alloys is the presence of precipitate free zones (PFZs) in the vicinity of GBs. The occurrence of PFZs is generally explained in term of either vacancy depletion or solute depletion. The vacancy depletion mechanism was independently proposed by Embury and Nicholson[1], and Tylor[9].Embury and Nicholson[1]assumedthatthe supersaturated solute needs a critical vacancy concentration to form a nucleus.Thus, a reduced vacancy concentration near the GB will inhibit the precipitation in their vicinity. Meanwhile, Tylor[9]believed that vacancy concentration above a critical value is indispensable for nucleation throughtheir effect on the diffusion of solute atoms, and reductionin the strain energy of nucleus. Instead of considering the vacancy concentration profile alone, the solute depletion mechanism also takes into account the solute concentration profile in the proximity of GBs, which suggests that the heterogeneous precipitation at GBs can consume the solute atoms in nearby matrix thus augmenting the size of subsequently formed PFZs [10].

Besides the formation mechanisms, the impact of PFZs on the mechanical performance of these age hardened alloys has also been extensively studied. Geisler[11]in 1951 initially proposed that intergranular fracture may arise from strain localization in PFZs near GBs in age hardened alloys. A study by Unwin and Smith[12] showed clear evidence of this localized GB shear in the PFZs in aged Al-Zn-Mg alloy, though they thought the area fraction of GB precipitates were more influential on the fracture toughness than the width of PFZs.Sedricks et al[13]observed a higher dislocation density in the region of the PFZ close to the side of the grain interior which was echoed by a later observation of Abe et al[14]in Al-Zn-Mg. Baither et al[15]observed that different slip systems were activated in PFZs at relatively low strength through in-situ tensile tests under transmission electron microcopy (TEM). They attributed the decrease of yield strength to the high dislocation multiplication rate, which further accelerated the dislocation pile-ups against the GB.Theoretical attempts were also explored to predict the fracture strain or toughness based on the properties of PFZs[16-19]. Until now, 
variousmechanical and corrosion properties have been reported to be related to the width of the PFZs, including yield strength[8], ductility[20], initial work hardening rate[14], fracture toughness[19], and stress corrosion cracking[21]. Although results are often inconsistent among different alloy systems, PFZs near GBsare soft layers where strain localization readily occurs.

Compared to PFZs in the vicinity of GBs, the PFZs around pre-existing second phase particles without heterogeneous nucleation on the GB is less studied [1, 3, 19]. Embury and Nicholson[1]noticed a PFZ around a primary carbide, and included its width as a parameter in determiningthe binding energy of vacancies and solute atoms. Sanders et al[3] observed a PFZ around $\mathrm{Al}_{6} \mathrm{Mn}$ intermetallic precipitates in a $\mathrm{Al}-\mathrm{Li}-\mathrm{Mn}$ alloy. But no measurement of the width of the PFZ around the precipitates was attempted due to the complicated shape of $\mathrm{Al}_{6} \mathrm{Mn}$ precipitate. Other than mirroring the formation mechanism at GBs, the question of whether there are alternative mechanisms that operate on the formation of PFZs around second phase particles remains open.

Here, we performed TEM studies to reveal that the PFZs around the primary carbides in alloy 725, depends on the variant. Finite element simulations were also conducted to correlate the stress field around the primary carbides to the shape of variant dependent PFZ. In addition to the vacancy depletion and solute depletion mechanisms, we found that the local stress or more precisely, the interaction energy also plays a significant role inthe width of PFZsaround the primary carbides. Our findings provide new insight to the formation mechanism of PFZs.

\section{Experimental and simulation details}

\subsection{Experiments}

The alloy 725 wasprovided by Carpenter Technology Corporation with heat number 416408. The chemical composition (in wt.\%) of the present alloyis $57.6 \mathrm{Ni}, 21.52 \mathrm{Cr}, 8.07 \mathrm{Mo}$, 7.94 Fe, 3.41Nb, 1.35 Ti, 0.17 Al, 0.011 C, 0.04Si, 0.04 Mn,0.02 Co, 0.004 P, 0.0006 S, 0.01Cu, $0.0032 \mathrm{~B}$. The as-received (AR) material was heat-treated by a standard procedure after hot work as follows: solid solution treated at $1038^{\circ} \mathrm{C}$ for $2 \mathrm{~h}$ and fan cooled, aged at $735^{\circ} \mathrm{C}$ for $8 \mathrm{~h}$ followed by a cooling rate of $56^{\circ} \mathrm{C} / \mathrm{h}$ to $621^{\circ} \mathrm{C}$, and held for another $8 \mathrm{~h}$. Specimens with $2 \times 2 \times 20 \mathrm{~mm}$ were cut from the AR billet using electro discharge machining (EDM). Electron backscatter diffraction (EBSD) specimens were mechanical polished down to 800 grit followed by cloth polishing with $1 \mu \mathrm{m}$ diamond paste, and then electro-polished. The electrolyte solution was a 20 vol.\% sulfuric acid in methanol solution and the polishing was performed at $-20^{\circ} \mathrm{C}$ at a voltage 
around 20V for 30s. The preparation of specimen for optical observation followed a similar procedure except the last step was etching instead of electro-polishing. Waterless Kalling'sreagent was used which is $5 \mathrm{~g} \mathrm{CuCl}_{2}$ in $100 \mathrm{ml} \mathrm{HCl}$ and $100 \mathrm{ml}$ Ethanol solution. The disks for transmission electron microscopy (TEM) experiments were prepared by mechanical grinding of $3 \mathrm{~mm}$ disks down to tens of microns. The disks were then perforated in a TenuPol-5 twinjet polisher with $20 \%$ sulfuric acid plus $80 \%$ vol. methanol solution with a voltage of $10 \sim 20$ $\mathrm{V}$ at $0{ }^{\circ} \mathrm{C}$. TEM experiments were performed using a JEOL 2010F and JEOL 3011 microscope operated at $200 \mathrm{kV}$ and $300 \mathrm{kV}$, respectively. Both Energy-dispersive X-ray (EDX) spectroscopy and EBSD were collected in a FEI Helios 650 system operating with a voltage of $20 \mathrm{keV}$. The step size for EBSD collection was $0.8 \mu \mathrm{m}$. The working distance for EBSD was $15 \mathrm{~mm}$.

\subsection{Finite elementcalculation}

Finite element (FE) method or FEM was applied to estimate the stress field around the primary particle. This stress field arosedue to difference in thermal expansion coefficients between matrix and $\mathrm{NbC}$ particles.The calculation was performed using the ABAQUS code[22]. The material constants employed in the FE analysis of alloy 725 are from open literature[23], and include the temperature dependent Young's modulus, Poisson's ratio, thermal expansion coefficient, yield strength, tensile strength and corresponding fracture strain. For NbC, plastic deformation was neglected since the particle is much more rigid than the matrix. In addition, the temperature dependence of elastic properties of $\mathrm{NbC}$ was ignored because the changes of these properties are relatively small in the temperature range interested. Therefore, for $\mathrm{NbC}$, only Young's Modulus $(=434 \mathrm{GPa})$, Poisson's Ratio $(=0.22)$, and coefficient of thermal expansion $\left(=6.7 \times 10^{-6} / \mathrm{C}^{\circ}\right)[24]$ were used in the $\mathrm{FE}$ analysis.

Fig. 1 shows the FE mesh of 21,703 four-node reduced integration elements. The simulation domain was selected to be the same as that shown in the accompanying TEM images which cover a size of approximately $1 \mu \mathrm{m}$ x $1 \mu \mathrm{m}$. Periodic boundary condition with a cell size10 times the particle size was selected corresponding to a particle density of $1 \times 10^{17} / \mathrm{m}^{3}$.A user subroutine, UVARM, was employed to calculate the interaction energy, $\Delta E$.

The temperature range chosen for FE simulation was designed to reflect the heat treatment schedule of $1038^{\circ} \mathrm{C}$ anneal for $2 \mathrm{hr}$ followed by aging at $735^{\circ} \mathrm{C}$ for $8 \mathrm{hr}$. Only the first aging treatment was considered because the nucleation of $\gamma^{\prime \prime}$ precipitates generally occurs at the initial stage of the first aging treatment[25]. The zero-stress condition for the FE calculation 
wasset to the annealing temperature of $1038^{\circ} \mathrm{C}$. At $1038^{\circ} \mathrm{C}$, the internal stress in the matrix will relax quickly due to the high dislocation mobility. The zero-stress conditions at $1008{ }^{\circ} \mathrm{C}$ and $1068{ }^{\circ} \mathrm{C}$ were also checked. The variation of stress was7\% within the temperature range of $1038 \pm 30^{\circ} \mathrm{C}$.No significant shift of zero contour line wasobservedamong the different zero-stress conditions. The variation of interaction energy wasabout the same level, $7.2 \%$.

Both plane stress and plane strain assumptions were tested in the FE calculation. The plane stress and plane strain conditionsyieldedslightly different predictions of the interaction energy. The interaction energy for plane stress condition waslarger in absolute value than that of the plane strain condition by a maximum of $20 \%$. However, the relative value of interaction energy between variants is the significant factor controllingbias precipitation. From this perspective, a similar prediction wasobtainedfor both assumptions. So for convenience, only the results from plane stress assumption were presented here.Ideally, 3-D simulation should be conducted due to the shape of the precipitates. However, the calculation was limited to the 2-D morphology of the primary particles because it was challengingto obtain the full 3-D shape of the same carbide particle together with the nearby nano-sized precipitates.In spite of this limitation, the calculation can still provide a qualitative estimate of the relative interaction energy between two variants, and provide physical insight into the bias selection of precipitatesand PFZ around the primary particles. Thus, a more precise calculation involving all the anisotropic properties of both particle and matrixis not pursuedin this study.

\section{Results}

\subsection{Microstructure characterization of alloy 725}

Annealing twins were frequently observed in the as-received (AR) alloy after the standard heat treatment as shown in Fig.2, Fig.3 and Fig.4. The twin boundaries (TB) were highlighted in red while the regular high angle grain boundaries were in black as shown in Fig.4b. The EBSDresult shows that the length fraction of TB, mainly $\Sigma 3$ boundary, is above $65 \%$ of the total length of GB. High fraction of these kinds of coincidence site lattice (CSL) boundaries enhance the corrosion resistance of these alloys in practical application[26]. No significant texture was identified as suggested by the inverse pole figure. Two types of primary particles were observed as shown in Fig.2 and Fig.3, which can be described by the formula (Nb,Ti)(C,N) vs. (Nb, Ti)C. The large particles were rich in $\mathrm{Ti}$ and $\mathrm{N}$ and appeared as stringers along the extrusion direction. The average particle size wasaround $\sim 5.5 \mu \mathrm{m}$. The chemical composition (in 
wt.\%) of a representative particle was $3.63 \mathrm{C}, 14.37 \mathrm{~N}, 0.89 \mathrm{Al}, 11.17 \mathrm{Nb}, 69.0 \mathrm{Ti}, 0.93 \mathrm{Cr}$ as shown in Fig.3c. The smaller particles were dominated by $\mathrm{Nb}$, Ti and $\mathrm{C}$ elements, and had an average size of $\sim 290 \mathrm{~nm}$. The EDXanalysis shown in Fig.3d indicated a chemical composition (in wt.\%) as follows: 10.7 C, 3.28 Al, 20.14 Nb, 7.78 Mo, 4.65 Ti, 14.31 Cr, 0.24 Mn, 5.22 Fe, 33.67 $\mathrm{Ni}$. Due to the small size of the particle compared to the interaction volume of electron beam, the matrix elements were inevitably collected. EDX measurements were taken at a minimum of five points on each of these particles. Specially, these $(\mathrm{Nb}, \mathrm{Ti}) \mathrm{C}$ particles were typically lined up and situated at the ghost boundaries as shown in Fig.2, Fig.3a-b and Fig.4a. Ghost grain boundaries are the locations of boundaries that were formed upon casting. Later, recrystallization after hot-work process freed the grain boundaries while the precipitates remained their original location. The average grain size of AR 725 alloy is around $\sim 60 \mu \mathrm{m}$. All the statistical results are given in Fig.5.

Fig.6a shows a substantial amount of precipitates within the matrix, with a density on the order of $\sim 3 \times 10^{22} / \mathrm{m}^{3}$. The selected area diffraction pattern (SADP) corresponded well to the $\gamma^{\prime \prime}$ phase, which is an ordered body-centered-tetragonal (bct) $\mathrm{D}_{22}$ structure with lattice parameters $a_{\gamma^{\prime \prime}}=b_{\gamma^{\prime}} \cong a_{\gamma}$, and $c_{\gamma^{\prime \prime}} \cong 2 a_{\gamma}$. A simple method of identifying the $\gamma^{\prime}$ phase involves the coprecipitation with $\gamma^{\prime \prime}$ andwasintroduced by Cozar and Pineau[27]. Using this approach, no $\gamma^{\prime}$ phase was identified at multiple positions which suggested that the amount of $\gamma^{\prime}$ phase is negligible. The established orientation relationship[27] between $\gamma^{\prime \prime}$ and matrix is (001) $\gamma^{\prime \prime} / /\{001\} \gamma$, and [100] $\gamma^{\prime \prime} / /<100>\gamma$. Three variants of $\gamma^{\prime \prime}$ phase were formed due to the symmetry of the matrix as shown in Fig.6b-d. The detailed orientation relationship was defined as follows, variant one $\left(\mathrm{V}_{1}\right):(001) \gamma^{\prime \prime} / /(100) \gamma,[001] \gamma^{\prime \prime} / /[100] \gamma$ or [ $\left.\overline{1} 00\right] \gamma ;$ variant two $\left(\mathrm{V}_{2}\right):(001) \gamma^{\prime \prime} / /(010) \gamma$, [001] $\gamma^{\prime \prime} / /[010] \gamma$ or $[0 \overline{1} 0] \gamma ;$ variant three $\left(\mathrm{V}_{3}\right):(001) \gamma^{\prime \prime} / /(001) \gamma,[001] \gamma^{\prime \prime} / /[001] \gamma$ or $[00 \overline{1}] \gamma$. The [001] $\gamma$ zone axis was explored because the three variants can be easily distinguished[28]. Also, images from this particular zone axis can provide information about both diameter and thickness of the $\gamma^{\prime \prime}$ phase. A vector was plotted in the direction of the c-axis of $\gamma^{\prime \prime}$ variants in the coordinate system of the matrix. Most of the observations in this study were performed in this direction as the diffraction spots of the three variants were distinguished without overlap with the matrix. The precipitates are disk-shaped with short dimension along the c-axis. The average diameter was around $18 \mathrm{~nm}$ and the average thickness was about $\sim 8 \mathrm{~nm}$ as the statistical results shown in Fig.5. 


\subsection{Precipitates free zone around primary carbides}

Fig.7a shows the PFZ around a primary particle. The extra diffraction spots derived fromthe primary particle correspond well to a (002) plane d-spacing of NbC which has a FCC structure with a lattice parameter of $0.447 \mathrm{~nm}$. Another similar particle was also indexed which again matched well with the lattice parameter of NbC (Fig.8). No orientation relationship can be identified between these (Nb,Ti)C particles and the matrix due to the incoherent interface. A potential reason for this observation is that after the nucleation of the $(\mathrm{Nb}, \mathrm{Ti}) \mathrm{C}$ precipitate, the orientation of the surrounding matrix was changed due to the recrystallization process, thus the orientation relationship between the matrix and particles was not maintained. The PFZ became apparent in dark field (DF) image (Fig.7b) of all three variants of $\gamma^{\prime \prime}$ precipitate. The width of the PFZ ranges from 50 90 nm. A dislocation line was observed in the STEM image in Fig.7c. An EDX line scan (Fig.7d) confirmed that the particle has a composition close to that of (Nb,Ti)C, which was similar to particles situated at ghost boundaries.

Surprisingly, these PFZs exhibiteda strong dependence on the variant, as shown in Fig.9a-c. Note that the orientation of matrix in the model (Fig. 9d) matches that of the TEM images and the orientation between matrix and $\gamma^{\prime \prime}$ particles is given on the images in Figs 9a-c. Even in a single variant scenario (for example, in Fig.9a), the size of the PFZ, marked as position one (P1) through position four (P4),variedaround the circumference of the particle. The smallest dimension of PFZoccurred at a corner of the primary particle (P1), with a size of $60 \mathrm{~nm}$. Meanwhile, the largest dimension occurred at a facet of the primary particle (P3), with a size of $\sim 450 \mathrm{~nm}$. For the second variant, Fig.9b, the shape of PFZ issimilar to that of the first variantwith a 90 degree rotation. The third variant (Fig.9c) was less affected by the shape of the particles, and the PFZ width around the periphery of the particle was uniform. Enhanced precipitation of the third variant was observed in the overlapped region of the PFZs related to variants one and two.The four points marked in Fig.9a,also represent different stress states around the precipitates according to Fig.9d-f. It should be noted that the physical and modeling length scales is kept consistent. The blue color stands for compressive stress while red indicates tensile stress. For example, the stressstate at position one (P1) is $\sigma_{11}^{A} \approx 200 \mathrm{MPa}, \sigma_{22}^{A} \approx-264 \mathrm{MPa}$, $\sigma_{12}^{A} \approx 0$. The stress states of the other three points werealso listed in Table1.

The precipitation was enhanced by a tensile stress along the c-axis direction of the variant, while a compressive stress along the c-axis of the same variant suppresses the precipitation. The 
in-plane stress had little effect on the third variant. To verify that the variant dependent PFZ was not limited to $[001] \gamma$ direction, the $[\overline{1} \overline{1} 1] \gamma$ zone axis wasinvestigated near another primary particle as shown in Fig.10, which was another direction with three distinguishable variants. The orientation relationship between matrix and $\gamma^{\prime \prime}$ is $(204) \gamma^{\prime \prime} / /\{202\} \gamma$, and [221] $\gamma^{\prime \prime} / /<111>\gamma$, which is consistent with $(001) \gamma^{\prime \prime} / /\{001\} \gamma$, and $[100] \gamma^{\prime \prime} / /<100>\gamma$. Again, a variant-dependent PFZ was observed around (Nb,Ti)C. Aligned $\gamma^{\prime \prime}$ precipitates were also noted following a crystallography direction close to [110] in Fig.10b and c. These precipitates were likely associated with dislocations at earlier stages. The strong variant dependence of PFZ was observed around every primary particle that examined (around 10 particles) in the materials, confirming that it was not an isolated event. Other examples were given in Fig.8.

\section{Discussion}

We will address the formation of variant-dependent PFZ in this section. The variantdependent PFZ in this study does not strictly follow the traditional description of PFZs, because of the presence of other variants within the PFZ of the examined variant such as those shown in Fig.9 and 10. Although the enhancement of precipitation of the third variant was observed at the position where both of the other two variants were denuded, the enhancement region tended to follow the shape of the overlapped PFZs of the other variants rather than a simple function of distance from the primary particle. Thus, the explanation of the variant dependent PFZ in terms of vacancy depletion or solute denudation that was caused by the sink strength of the primary particle is insufficient. This fact leads naturally to the suggestion that the stress field around the primary particle should be taken into consideration in the nucleation process of precipitates. Therefore, the variant-dependent PFZ can be understood as a superposition of two types of zones governed by different underlying mechanisms: the first one is a diffusion zone related to the sink strength of the primary particle, and the second one is a stress-influenced zone. It has been shown that the directional stress affected the priority and quantity of precipitation among different variants[29]. The process is also known as stress induced variant selection in which the stress determines the variant that forms around the primary particles. The diffusion-affected zone corresponds to the non-variant dependent part of PFZ as shown in Fig.7. The short dimension in the variant-dependent PFZ (Fig.9a)also reflects the diffusion zone by simply assuming that the diffusivity of vacancies or interstitials is isotropic around the primary particle. It is worth noting that the stress affected zone is larger than the diffusion zone (note the different dimension of 
variant-dependent PFZ in Fig.9). In contrast, the size of non-variant dependent part of PFZ is equivalent to the size of the variant dependent PFZ if the stress influence is negligible such as the case in Fig.9c.

Although the presence of the stress affected zone around a primary particle is a new observation, no new principle is involved. The effect of external stress on the nucleation and growth of precipitates has been frequently addressed [29-34]. In this study, we shall discuss the effect of the stress (internal stress caused by differential thermal coefficient difference between the primary particle and matrix) on the nucleation of $\gamma^{\prime \prime}$ precipitates instead. Generally, the free energy changed $\Delta F_{t}$ due to the nucleation of a new phase can be written as[35]:

$$
\Delta F_{t}=V_{\beta} \Delta F_{\alpha \beta}^{V}+A_{\beta} \sigma+V_{\beta} \Delta F_{E}^{V}
$$

where $V_{\beta}$ is the volume of $\gamma^{\prime \prime}$ precipitates, $A_{\beta}$ is the interface area between $\gamma^{\prime \prime}$ and matrix, $\Delta F_{\alpha \beta}^{V}$ is the volume free energy change, $\sigma$ is the specific energy of new interface, $\Delta F_{E}^{V}$ is the increase of elastic strain energy per unit volume of $\gamma^{\prime \prime}$ precipitate. We assume that the stress does not affect the first two terms, but the elastic strain energy term will be changed due to an interaction between applied stress and the transform strain of $\gamma^{\prime \prime}$ precipitate. In other words, this interaction energy can be directly added into the third term. This interaction energy was analytically solved by Eshelby in his classic model[36, 37], and can be simply written as follows (assuming $\sigma_{i j}^{A}$ varies slowly with the position):

$$
\Delta E_{E}^{V}=\frac{\Delta E_{E}}{V}=-\frac{1}{2} \sigma_{i j}^{A} e_{i j}^{T}
$$

where $\triangle \mathrm{E}_{\mathrm{E}}$ is the interaction energy, $\Delta E_{E}^{V}$ is the specific interaction energy, $\sigma_{i j}^{A}$ is the applied stress which is the stress field due to the primary particle, $e_{i j}^{T}$ is the stress-free strain of $\gamma^{\prime \prime}$ nuclei, $V$ is the volume of the nucleus. As an example, the [100] variant $\left(\mathrm{V}_{1}\right)$ of $\gamma^{\prime \prime}$ has its $c$-axis parallel to the [100] direction of the matrix, and the stress-free strain of transformation is $e_{11}^{T}=\left(1 / 2 c_{\gamma^{\prime \prime}}\right.$ $\left.a_{\gamma}\right) / a_{\gamma} \approx 0.0249, e_{22}^{T}=e_{33}^{T}=\left(a_{\gamma^{\prime \prime}}-a_{\gamma}\right) / a_{\gamma} \approx 0.00277$, where the lattice parameters for $\gamma^{\prime \prime}$ and $\gamma$ phase are $a_{\gamma^{\prime \prime}}=b_{\gamma^{\prime \prime}}=0.362 \mathrm{~nm}, c_{\gamma^{\prime \prime}}=0.74 \mathrm{~nm}$ and $a_{\gamma^{\prime}}=0.361 \mathrm{~nm}$, respectively[38]. The shear strain $e_{i j}^{T}(\mathrm{i} \neq \mathrm{j})$ was commonly assumed to be zero for a tetrahedral distortion[39]. Recall the stress state at position one (P1) in Fig.9a, $\sigma_{11}^{A} \approx 200 \mathrm{MPa}, \sigma_{22}^{A} \approx-264 \mathrm{MPa}, \sigma_{12}^{A} \approx 0$, for which the specific interaction energy for variant one $\left(\mathrm{V}_{1}\right)$ is calculated to be $\Delta E_{E}{ }^{V} \approx-2.1 \mathrm{MJ} / \mathrm{m}^{3}$. For $\mathrm{V}_{2}$, the stress- 
free strain is $e_{11}^{T}=e_{33}^{T} \approx 0.00277$, and $e_{22}^{T} \approx 0.0249$, thus the specific interaction energy is $\Delta E_{E}{ }^{V} \approx 3.0 \mathrm{MJ} / \mathrm{m}^{3}$.The specific interaction energy $\Delta E_{E}{ }^{V}$ can directly contribute to the elastic strain energy $\Delta F_{E}^{V}$. A negative value of $\Delta E_{E}^{V}$ means that elastic strain energy will be relaxed by the stress field of the primary particle, thus facilitating the nucleation of $\gamma^{\prime \prime}$ phase. Considering that Young's modulus of alloy 725 is around $204 \mathrm{GPa}$, a 1\% strain would yield an elastic energy of $10 \mathrm{MJ} / \mathrm{m}^{3}$. The interaction energy of $-2.1 \mathrm{MJ} / \mathrm{m}^{3}$ is substantial compared to the elastic energy of $1 \%$ strain. So at P1, the lower interaction energy $V_{1}$ is favored over $V_{2}$. Meanwhile, at P2, the interaction energy reverses, then $V_{2}$ is favored instead. The interaction energy for $V_{1}$ and $V_{2}$ were calculated as shown in Fig.9g and h respectively. The calculated values are in qualitative agreement with the experimental observations, in that at a point where the variant has negative interaction energy the precipitate is favored. This observation is in agreement with previous observation [29]. Weillustrate the effect of stress on the bias precipitation using a schematic diagram in Fig.11. At zero stress state, all the variants precipitate simultaneously within the matrix. When stress is applied, different variants will suffer from different elastic energy $F_{E}$ (caused by the interaction energy term $E_{E}$ ). The variant with lower effective free energy $\left(F_{t}\right)$ will precipitate first by the common tangent rule. From this point, only the relative interaction energy value will be sufficient to predict which variant forms first.

However, the precipitation behavior at positions P3 and P4 where the shear stress is significant and normal stresses are low, was not explained by the current 2-dimensional FE calculations. In this case, the interaction energy from the third variant has to be considered. The absence of precipitation of $\mathrm{V}_{1}$ and $\mathrm{V}_{2}$ at $\mathrm{P} 3$ and P4 was likely caused by the favored nucleation of the third variant, as experimentally observed in this study. Unfortunately, due to the lack of 3dimensional information on the shape of primary carbides, the true stress state and interaction energy were not determinable for $\mathrm{V}_{3}$. So this point cannot be verified.

The full anisotropic elastic propertiesof carbide and matrix were not incorporated in current FEM. The potential impact of anisotropic elastic properties (modulus and Poisson's ratio) to the interaction energy, which is the most important indicator of bias precipitation, is discussed here. From the Hooke's law, the change of modulus and Poisson's ratio will inevitably affect the stress values. The interaction energy will be also changed accordingly.However, the absolute interaction energy of any variantis less important compared with the difference between that of 
two variants.Applying Eq.(2) to both variants, and incorporatingtheHooke's law in plane stress condition, the difference of specific interaction energy is as follows:

$$
\Delta E_{E \text { Variant } 1}^{V}-\Delta E_{E \text { Variant } 2}^{V}=-1.23 \times 10^{2}\left(\sigma_{11}-\sigma_{22}\right)=-1.23 \times 10^{2} \frac{E}{(1+v)}\left(\varepsilon_{11}-\varepsilon_{22}\right)
$$

where $\varepsilon_{11}$ and $\varepsilon_{22}$ are strain components along $\mathrm{x}(\gamma[100])$ and $\mathrm{y}(\gamma[010])$ direction, respectively, for the matrix. Note that the $E$ and $v$ here are orientation dependent. From Eq.(3), the difference in specific interaction energy between two variants is dependent on the difference of $\varepsilon_{11}$ and $\varepsilon_{22}$. For an infinitesimal volume at $\mathrm{P} 1$, since the outward normal of the particle is in the $y$ direction, themismatchstrain, $\varepsilon_{22}$, can be estimated by:

$\varepsilon_{22}=\left(\alpha_{T, m}-\alpha_{T, p}\right) \Delta T$

where $\alpha_{\mathrm{T}}$, mand $\alpha_{\mathrm{T} \text {,p }}$ arethermal expansion coefficients of matrix and particle, respectively. $\Delta \mathrm{T}$ is the temperature difference between final and startingtemperature. As, $\alpha_{\mathrm{T}, \mathrm{m}}>\alpha_{\mathrm{T}, \mathrm{p}}$ in the temperature range interested, and $\Delta T=-303^{\circ} \mathrm{C}, \quad \varepsilon_{22}$ will alwaysbe negative at P1. Considering the positivePoisson's ratio around the point, $\varepsilon_{11}$ will always be a positive value. So the specific interaction energy of variant one is alwayslower than that of variant two, even though $E$ and $v$ are orientation dependent. Therefore,variant one will be favored. From this perspective, the current simulation provides a qualitative explanationof the bias precipitationaround the primary carbides.

\section{Conclusion}

A variant dependent PFZ of $\gamma^{\prime \prime}$ phase was for the first time observed around primary carbides(Nb,Ti)C in alloy 725. $\gamma^{\prime \prime}$ nucleation is governed by two factors, the transformation strain, and the stress field around the primary carbides. The asymmetry in the PFZ around the primary carbides is due to the stress field caused by the mismatch in thermal expansion coefficient between carbides and matrix. The stress field also determines which variant of $\gamma^{\prime \prime}$ will form for any particular location around the primary carbides. This new finding explains the anisotropy of variant nucleation around primary carbides and highlights the importance of internal stress on precipitate nucleation. It may also explain the precipitation behavior during pre-ageing deformation where significant internal stress was introduced. 


\section{Acknowledgements}

M.S and G.S.Wacknowledge the financial support by EPRI (contracts 10002164 and 10002154) and DOE (contract 4000136101). J.F.W acknowledges China Postdoctoral Science Foundation (Contract 2015M581543). M.S. also thanks Dr. Wenjun Kuang for assistant with EBSD

experiments. Access to the microscopes of the Electron Microscopy Analysis Laboratory (EMAL) at University of Michigan is also acknowledged. 


\section{References}

[1] J. Embury, R. Nicholson. The nucleation of precipitates: the system Al-Zn-Mg, Acta Metall. 13 (1965) 403-417.

[2] H. Rosenbaum, D. Turnbull. Metallographic investigation of precipitation of silicon from aluminum, Acta Metall. 7 (1959) 664-674.

[3] T. Sanders, E. Ludwiczak, R. Sawtell. The fracture behavior of recrystallized Al-2.8\% Li-0.3\% Mn sheet, Materials Science and Engineering 43 (1980) 247-260.

[4] J. Clark. Transmission electron microscopy study of age hardening in a Mg-5 wt.\% Zn alloy, Acta Metall. 13 (1965) 1281-1289.

[5] M. Raghavan. Microanalysis of precipitate free zones (PFZ) in Al-Zn-Mg and Cu-Ni-Nb alloys, Metall. Trans. A 11 (1980) 993-999.

[6] M. Raghavan. Precipitation in a Cu-30 Pct Ni-1 Pct Nb alloy, Metall. Trans. A 8 (1977) 1071-1078.

[7] R. Maldonado, E. Nembach. The formation of precipitate free zones and the growth of grain boundary carbides in the nickel-base superalloy NIMONIC PE16, Acta Mater. 45 (1997) 213-224.

[8] T. Krol, D. Baither, E. Nembach. The formation of precipitate free zones along grain boundaries in a superalloy and the ensuing effects on its plastic deformation, Acta Mater. 52 (2004) 2095-2108.

[9] J. Taylor. Effect of heat-treatment on grain-boundary zones in high-purity Al-Zn-Mg alloy vol. 92: Journal of the institute of metals, 1964. p.301.

[10] P. Unwin, G. Lorimer, R. Nicholson. The origin of the grain boundary precipitate free zone, Acta Metall. 17 (1969) 1363-1377.

[11] A. Geisler. Phase transformations in solids, New York 387 (1951).

[12] P. Unwin, G. Smith. The microstructure and mechanical properties of Al-6 percent Zn-3 percent Mg, J Inst Metals 97 (1969) 299-310.

[13] A. Sedriks, P. Slattery, E. Pugh. DEFORMATION WITHIN PRECIPITATE-FREE ZONES IN AN AGED AL-ZN-MG ALLOY, ASM TRANS QUART 62 (1969) 815-818.

[14] M. Abe, K. Asano, A. Fujiwara. Influence of the precipitate-free zone width on the tensile properties of an Al-6 Wt pct Zn-1.2 Wt pct Mg alloy, Metall. Trans. 4 (1973) 1499-1505.

[15] D. Baither, T. Krol, E. Nembach. In-situ transmission electron microscopy study of dislocation processes at precipitate-free zones in a $\gamma^{\prime}$-strengthened superalloy, Philos. Mag. 83 (2003) 4011-4029.

[16] T. Kawabata, O. Izumi. Ductile fracture in the interior of precipitate free zone in an Al6.0\% Zn-2.6\% Mg alloy, Acta Metall. 24 (1976) 817-825.

[17] E. Hornbogen, M. Gräf. Fracture toughness of precipitation hardened alloys containing narrow soft zones at grain boundaries, Acta Metall. 25 (1977) 877-881.

[18] J.D. Embury, E. Nes. On the tensile fracture of aluminium alloys, Zeitschrift für Metallkunde 65 (1974) 45-55.

[19] T. Morgeneyer, M. Starink, S. Wang, I. Sinclair. Quench sensitivity of toughness in an Al alloy: Direct observation and analysis of failure initiation at the precipitate-free zone, Acta Mater. 56 (2008) 2872-2884.

[20] N. Ryum. The influence of a precipitate-free zone on the mechanical properties of an AlMg-Zn alloy, Acta Metall. 16 (1968) 327-332. 
[21] A. Sedriks, P. Slattery, E. Pugh. PRECIPITATE-FREE ZONES AND STRESSCORROSION CRACKING IN A TERNARY Al-Zn-Mg ALLOY. DTIC Document, 1969.

[22] ABAQUS. Version 6.10 ed. Providence. Dassault Systèmes (2010).

[23] Available Products and Specifications: INCONEL ${ }^{\circledR}$ alloy 725, Publiscation NO.SMC066. Special Metals Corporation (2005).

[24] Niobium Carbides, Available on www.metweb.com.

[25] L. Shoemaker. Alloys 625 and 725: trends in properties and applications, Superalloys 718 625-706.

[26] P. Lin, G. Palumbo, U. Erb, K. Aust. Influence of grain boundary character distribution on sensitization and intergranular corrosion of alloy 600, Scripta Metallurgica et materialia 33 (1995) 1387-1392.

[27] R. Cozar, A. Pineau. Morphology of y'and y" precipitates and thermal stability of inconel 718 type alloys, Metall. Trans. 4 (1973) 47-59.

[28] S. Hong, W. Chen, T. Wang. A diffraction study of the $\gamma$ "phase in INCONEL 718 superalloy, Metall. Mater. Trans. A 32 (2001) 1887-1901.

[29] J. Oblak, D. Paulonis, D. Duvall. Coherency strengthening in Ni base alloys hardened by DO22 $\gamma^{\prime}$ precipitates, Metall. Trans. 5 (1974) 143-153.

[30] J. Tien, S. Copley. The effect of uniaxial stress on the periodic morphology of coherent gamma prime precipitates in nickel-base superalloy crystals, Metall. Trans. 2 (1971) 215-219.

[31] T. Eto, A. Sato, T. Mori. Stress-oriented precipitation of GP Zones and $\theta^{\prime}$ in an AI $\square \mathrm{Cu}$ alloy, Acta Metall. 26 (1978) 499-508.

[32] T. Miyazaki, K. Nakamura, H. Mori. Experimental and theoretical investigations on morphological changes of $\gamma^{\prime}$ precipitates in Ni-Al single crystals during uniaxial stress-annealing, J. Mater. Sci. 14 (1979) 1827-1837.

[33] B. Skrotzki, G. Shiflet, E. Starke Jr. On the effect of stress on nucleation and growth of precipitates in an Al-Cu-Mg-Ag alloy, Metall. Mater. Trans. A 27 (1996) 3431-3444.

[34] A. Zhu, E. Starke. Stress aging of Al-xCu alloys: experiments, Acta Mater. 49 (2001) 2285-2295.

[35] R. Doherty. Diffusive phase transformations in the solid state, Physical metallurgy 2 (1996) 1456-1458.

[36] J.D. Eshelby. The determination of the elastic field of an ellipsoidal inclusion, and related problems. Proceedings of the Royal Society of London A: Mathematical, Physical and Engineering Sciences, vol. 241: The Royal Society, 1957. p.376-396.

[37] J. Eshelby. The elastic field outside an ellipsoidal inclusion. Proceedings of the Royal Society of London A: Mathematical, Physical and Engineering Sciences, vol. 252: The Royal Society, 1959. p.561-569.

[38] S. Mannan, F. Veltry. Time-Tempearature-Trasnformation Diagram of Alloy 725, TMS, 2001.

[39] R.L. Fleischer. Solution hardening by tetragonal dist ortions: Application to irradiation hardening in FCC crystals, Acta Metall. 10 (1962) 835-842. 
Table 1. Stress tensors at four locations around a primay particle in Fig.9. Only two dimesional stress state was considered.

\begin{tabular}{lllllll}
\hline Position & \multicolumn{3}{c}{ StressTensor $(\mathrm{MPa})$} & \multicolumn{2}{c}{ Interaction Energy $\left(\mathrm{MJ} / \mathrm{m}^{3}\right)$} \\
\cline { 2 - 7 } & $\sigma_{11}$ & $\sigma_{12}$ & $\sigma_{21}$ & $\sigma_{22}$ & $\mathrm{~V}_{1}$ & $\mathrm{~V}_{2}$ \\
\hline 1 & $\sim 200$ & $\sim 0$ & $\sim 0$ & $\sim-264$ & $\sim-2.1$ & $\sim 3$ \\
2 & $\sim-214$ & $\sim 0$ & $\sim 0$ & $\sim 196$ & $\sim 2.4$ & $\sim-2.1$ \\
3 & $\sim 0$ & $\sim-158$ & $\sim-158$ & $\sim 0$ & $\sim 0$ & $\sim 0$ \\
4 & $\sim 0$ & $\sim 169$ & $\sim 169$ & $\sim 0$ & $\sim 0$ & $\sim 0$ \\
\hline
\end{tabular}




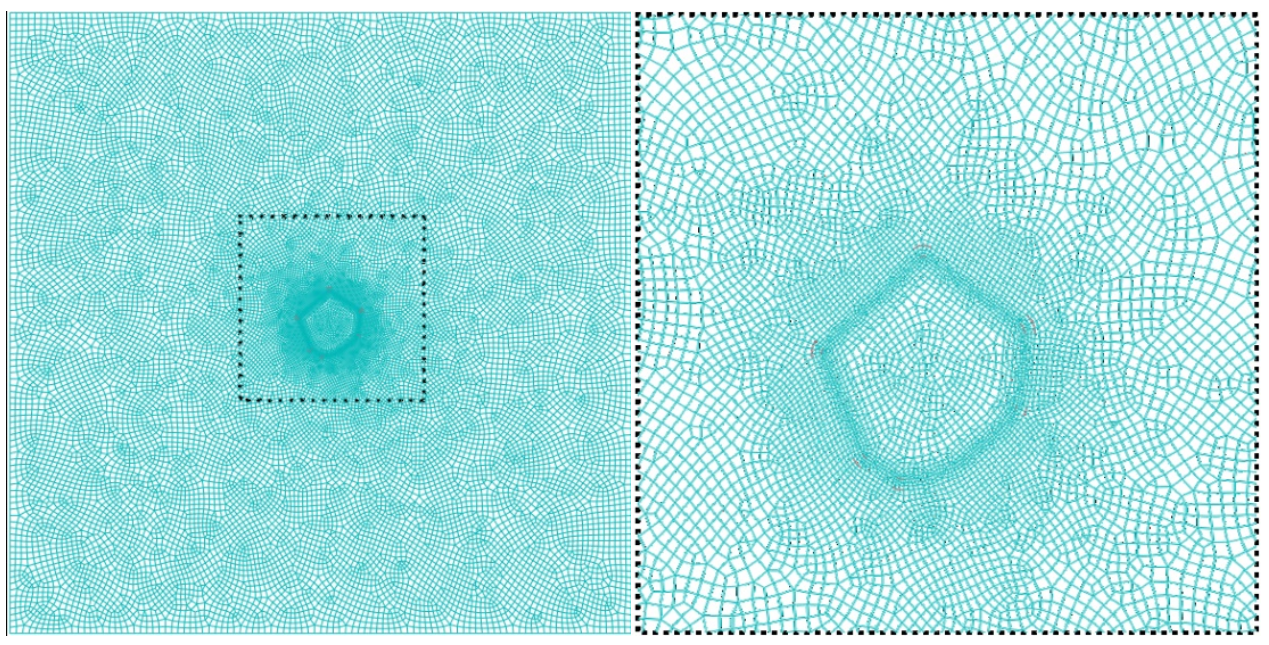

Fig.1FE mesh used to model the matrix containing a primary particle. A periodic boundary condition was assumed for the calculation. The length scale used for the model is consistent with the physical size of the particle.

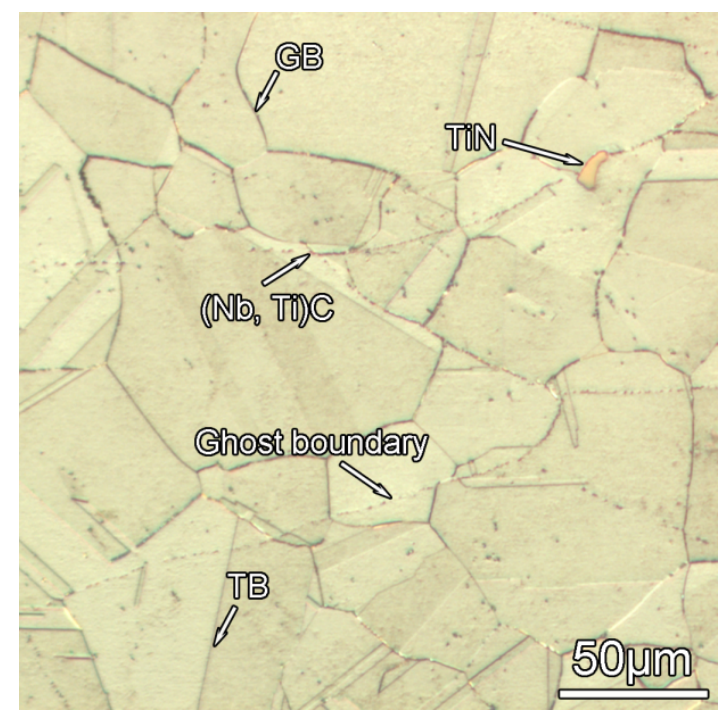

Fig.2 Optical microscope shows the basic structure of alloy 725 etched by waterless Kalling's solution. The larger primary particles are TiN and the smaller ones are (Nb,Ti)C. The ghost boundary are decorated by the (Nb, Ti)C particles. 


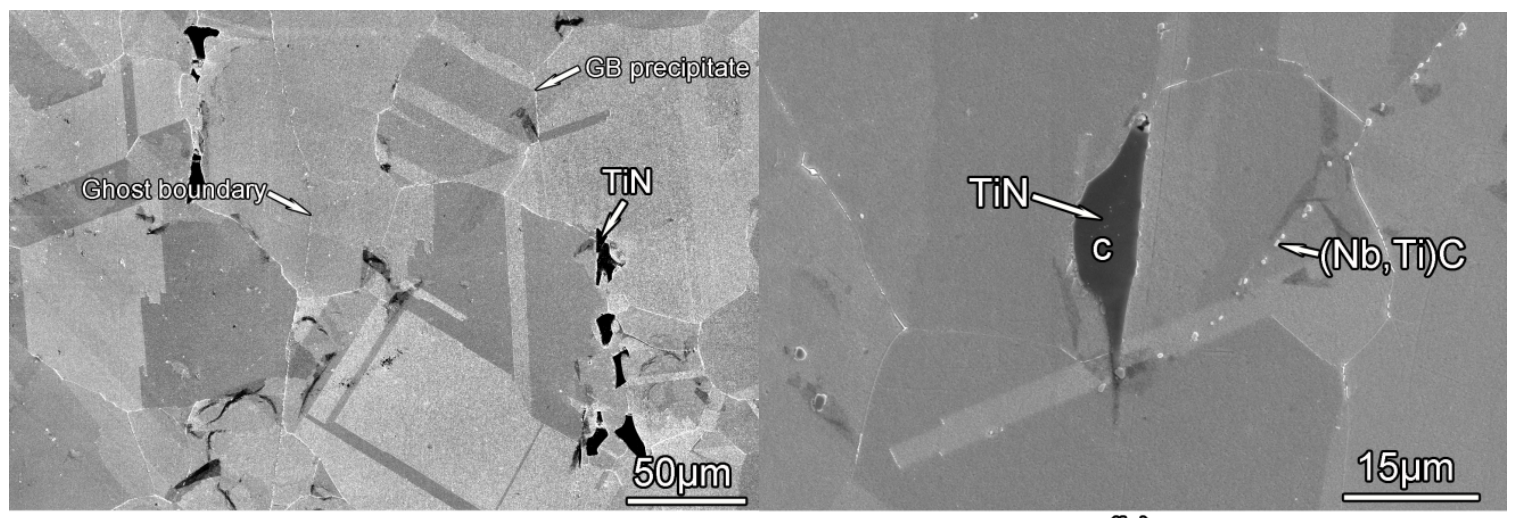

(a)

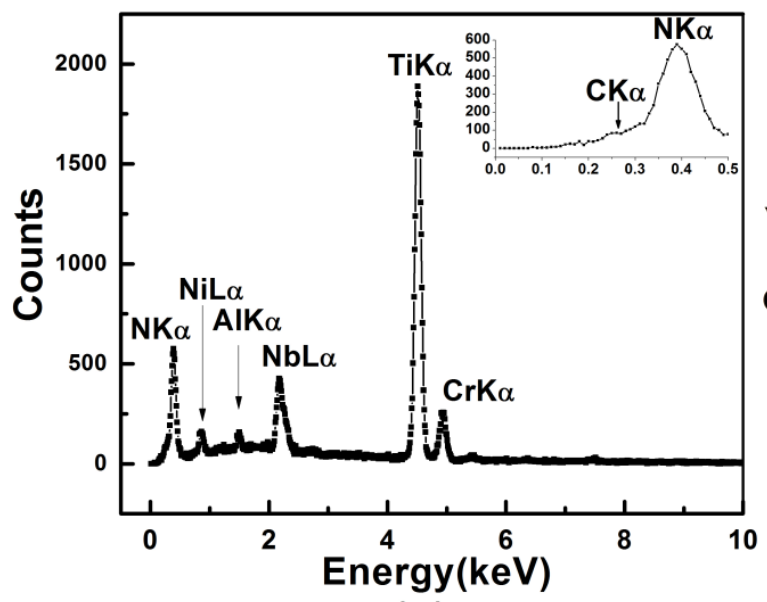

(c)

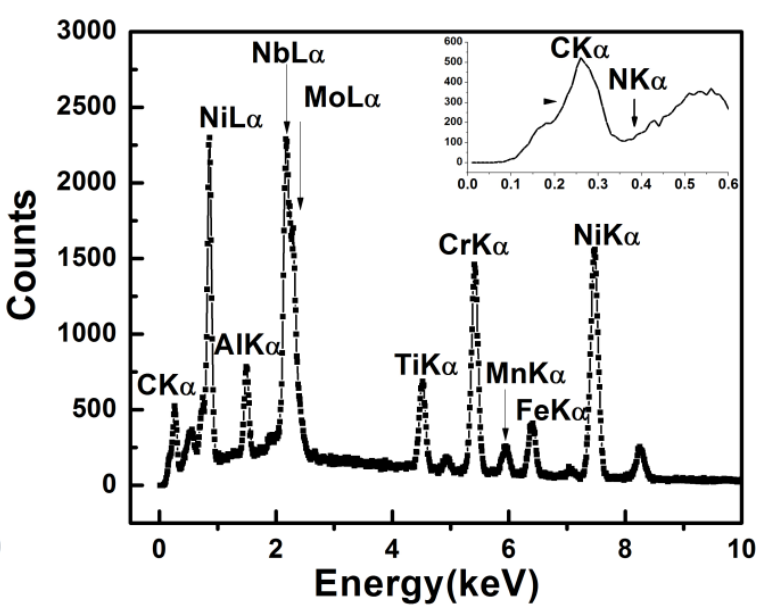

(d)

Fig.3 Secondary electron image and EDX of alloy 725. (a) Secondary electron image shows the basic structure of alloy 725.(b) The large black particles are commonly Ti, N riched (Ti,Nb)(C,N) as revealed by (c). (d) The EDX of a small particle similar to those marked as (Nb,Ti)C in (b) shows the enrichement of $\mathrm{Nb}, \mathrm{Ti}$ and $\mathrm{C}$ elements. The inserted EDX with an energy range from $0 \sim 0.6 \mathrm{keV}$ reaveals the relative content of $\mathrm{N}, \mathrm{C}$ elements are different in these kind of particles. An unindetified grain boundary precipitates are noted as the white line along the GB. 


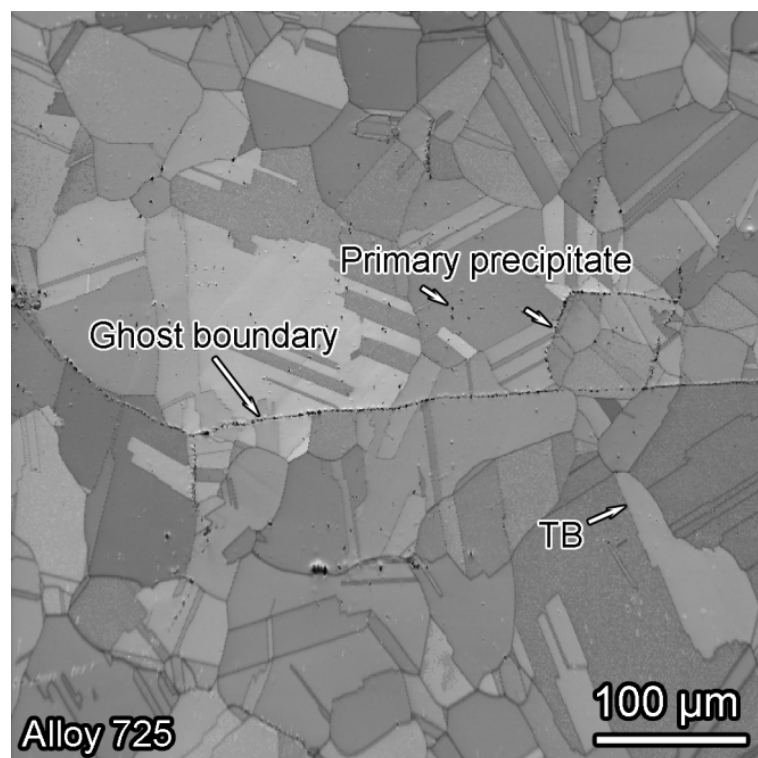

(a)

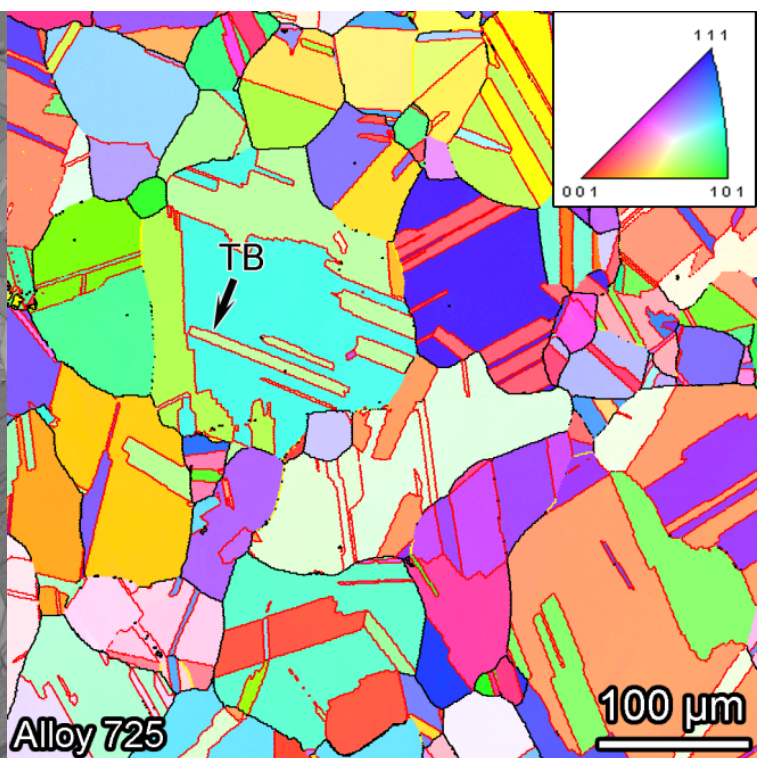

(b)

Fig.4 Electron backscatter diffraction (EBSD) map of alloy 725. (a) Image quality (IQ) map shows that the precipitates are decorated along the ghost boundaries, where grain boundaries of deformed casting grains located before recrystallization. (b) OIM map reveals significant amount of annealing twins in alloy 725 . The color code of grains reflects their position in the inverse pole figure (IPF) map. 


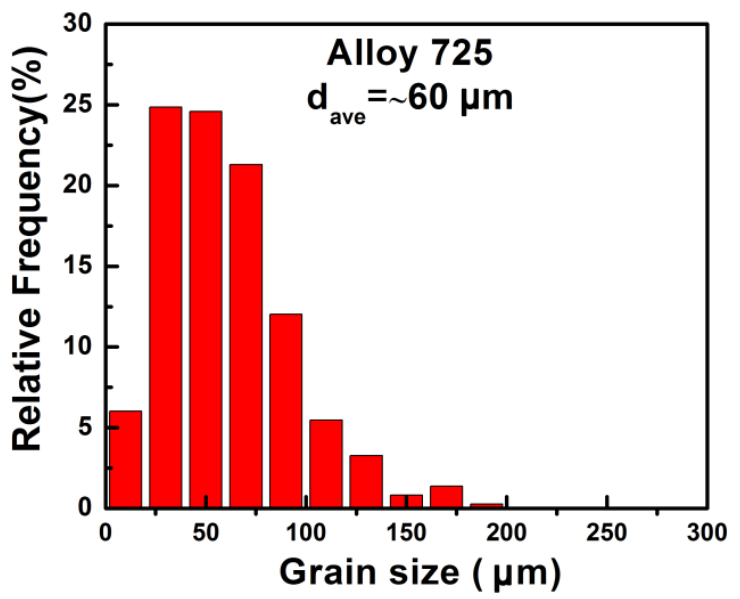

(a)

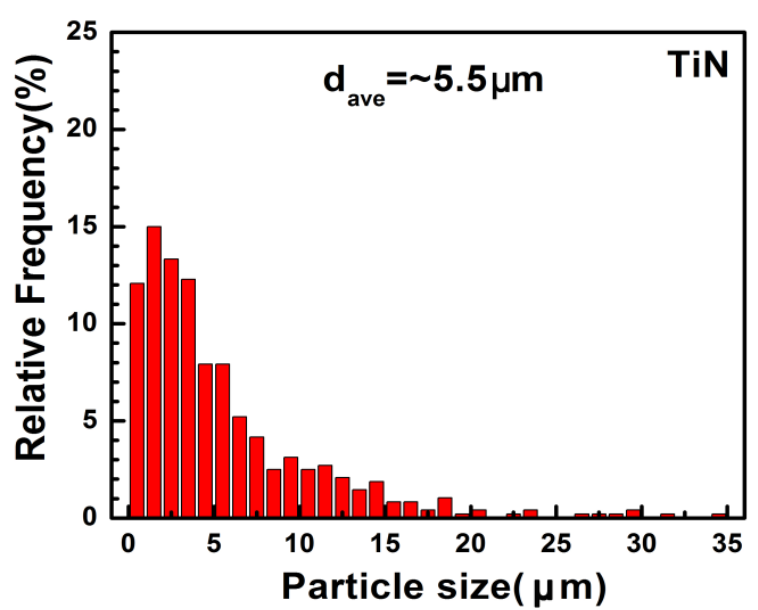

(c)

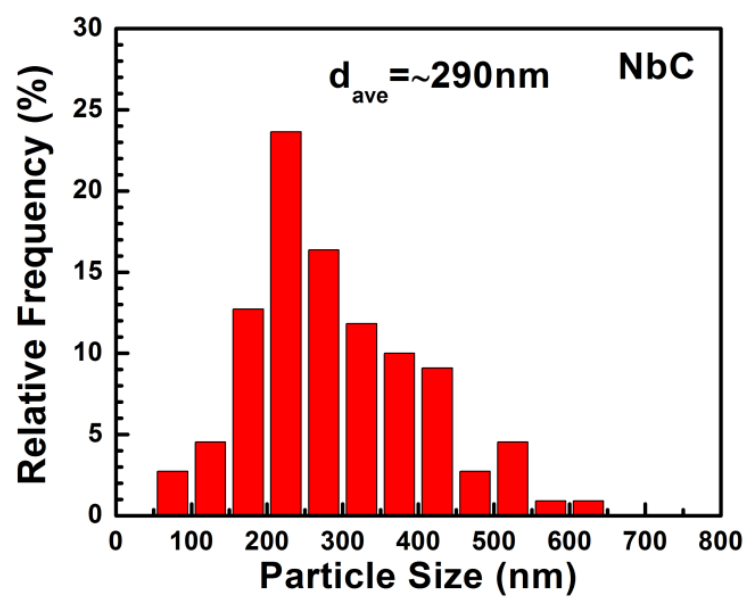

(b)

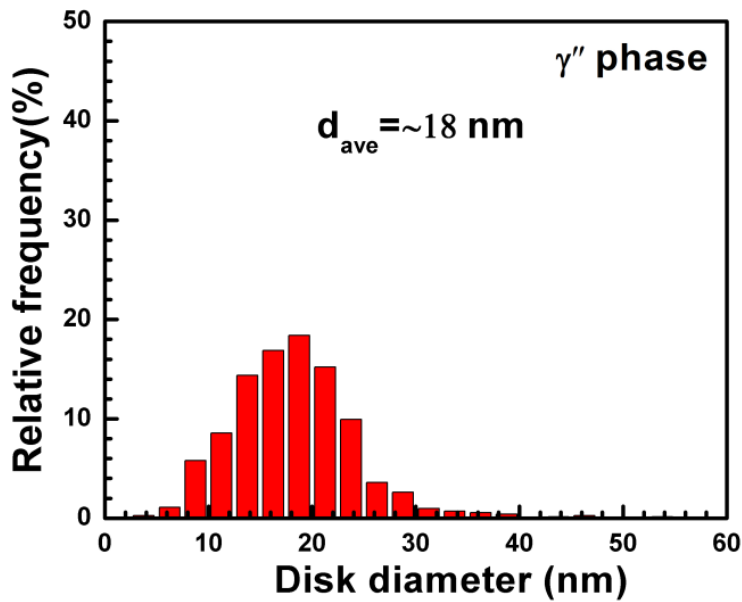

(d)

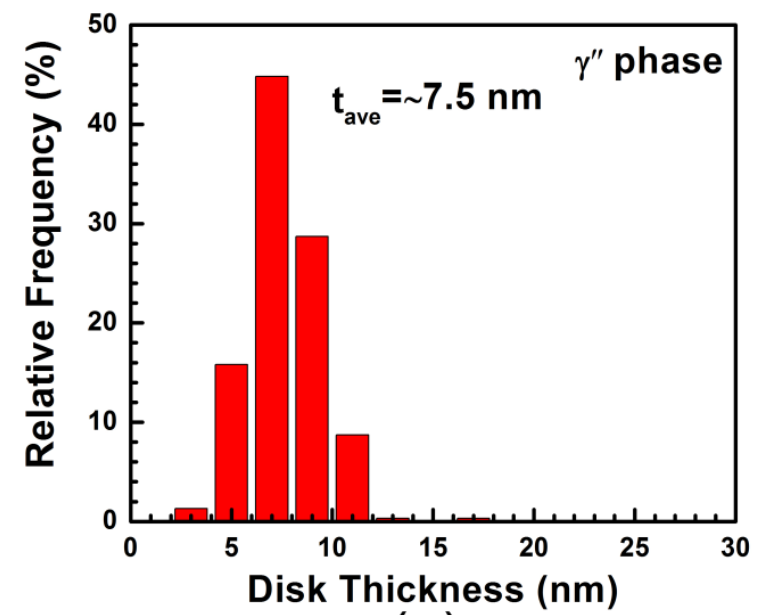

(e)

Fig.5 Grain size and particle size distribution of alloy 725. (a) Grain size based on optical images with 350 grains involved. (b) NbC particle based on TEM images, 60 particles involved. (c) TiN particles based on SEM images, 480 particles invovled. (d) Diameter of $\gamma^{\prime \prime}$ precipitate (730 
particles) and (e) Thickness of $\gamma^{\prime \prime}$ precipitate (310 particles). Noted: no critical size was identified that the $(\mathrm{Nb}, \mathrm{Ti})(\mathrm{C}, \mathrm{N})$ transform from TiN rich to $\mathrm{NbC}$ dominant particles.
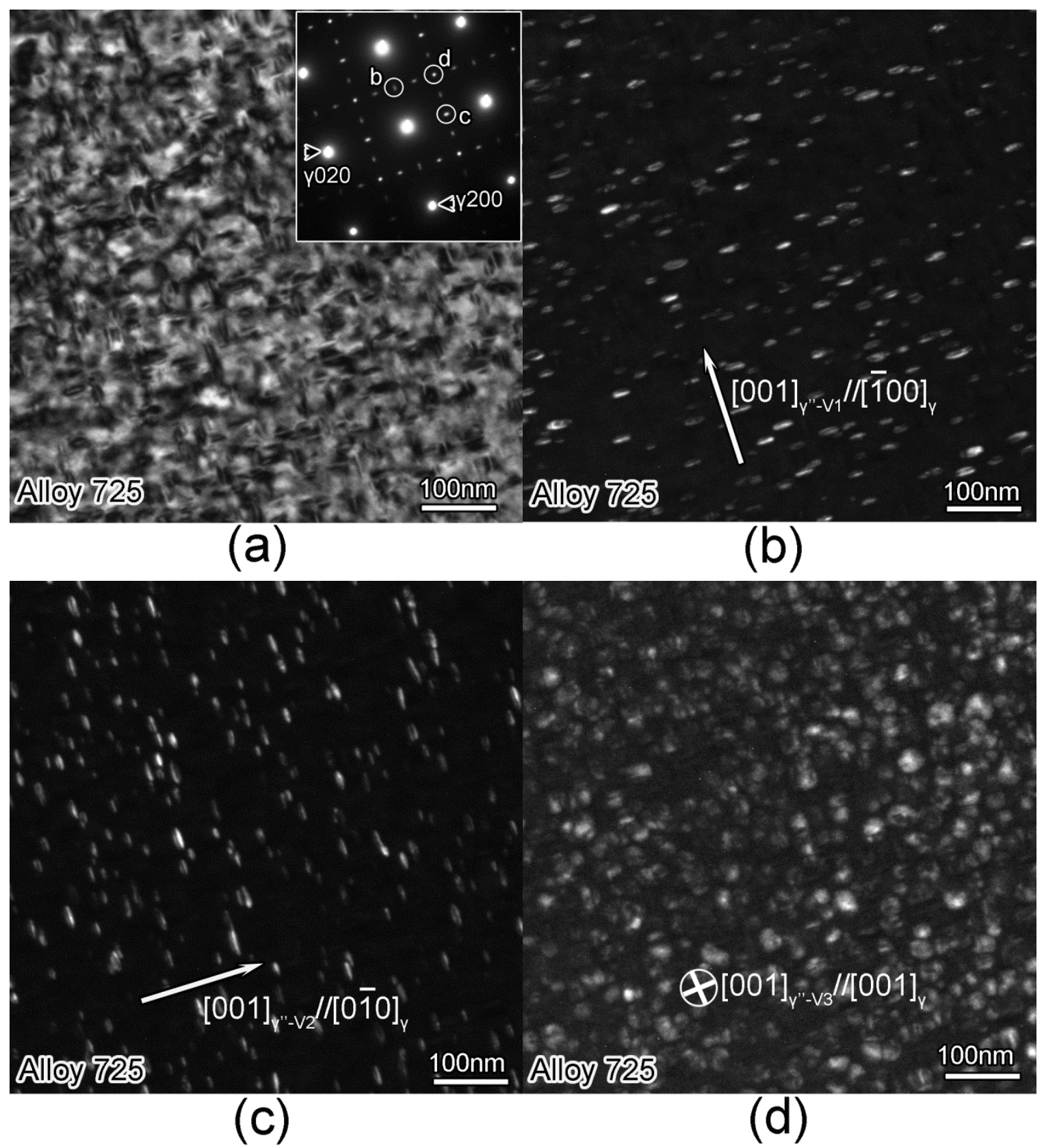

Fig.6 Bright field (BF) and dark field (DF) TEM images of $\gamma^{\prime \prime}$ precipitate.(a) BF image shows that massive precipitates are homogeneously distributed within the grain. (b-d) DF TEM images show all three variants of $\gamma^{\prime \prime}$ precipitate respectively using the spots circled in selected area diffraction pattern (SADP) inserted in (a). c-axis of $\gamma^{\prime \prime}$ phase was marked by an arrow with corresponding direction of the matrix. 


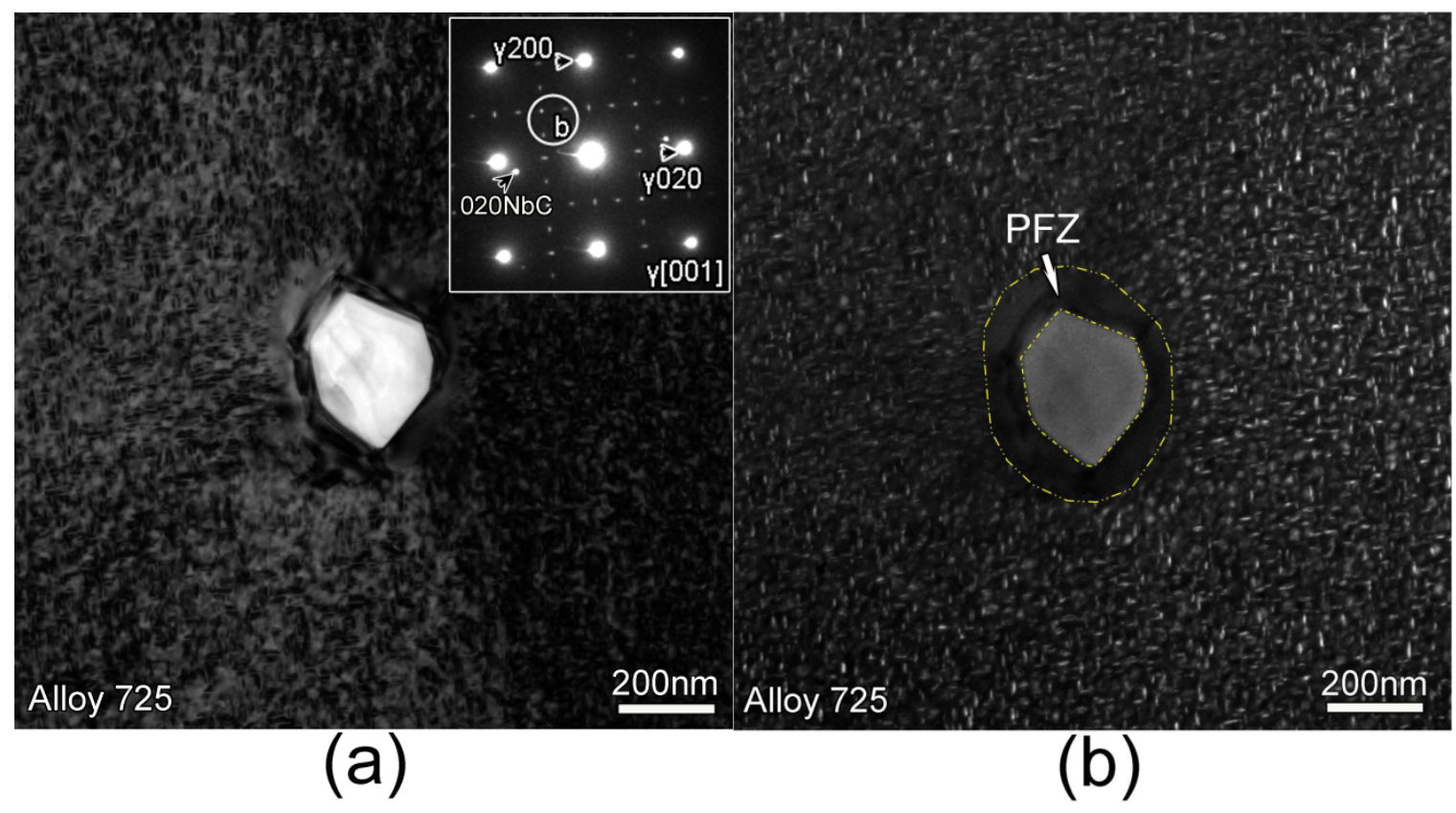

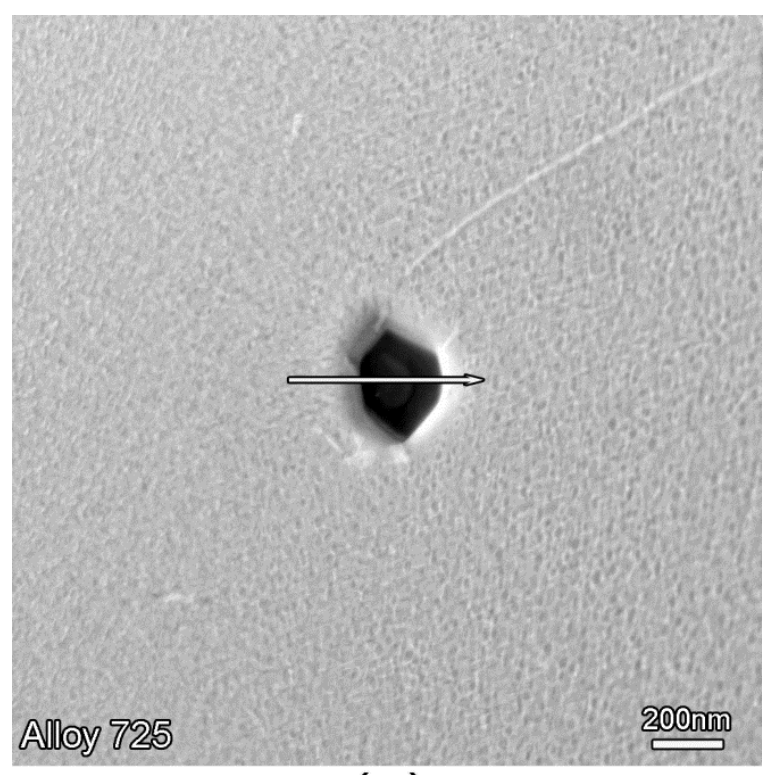

(c)

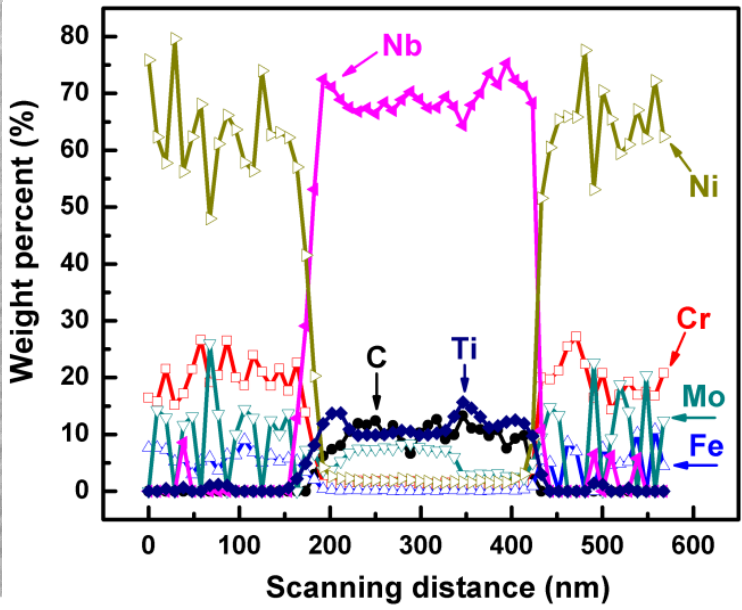

(d)

Fig.7 PFZ in the vicinity of a primary particle.(a) BF TEM image shows inhomogeneous distribution of $\gamma^{\prime \prime}$ precipitate around a primary particle. (b) PFZ is clearly visible in DF TEM image. (c) STEM image and (d) corresponding EDX line scanrevealing that primary particle is rich in $\mathrm{Nb}$, Ti and $\mathrm{C}$. 

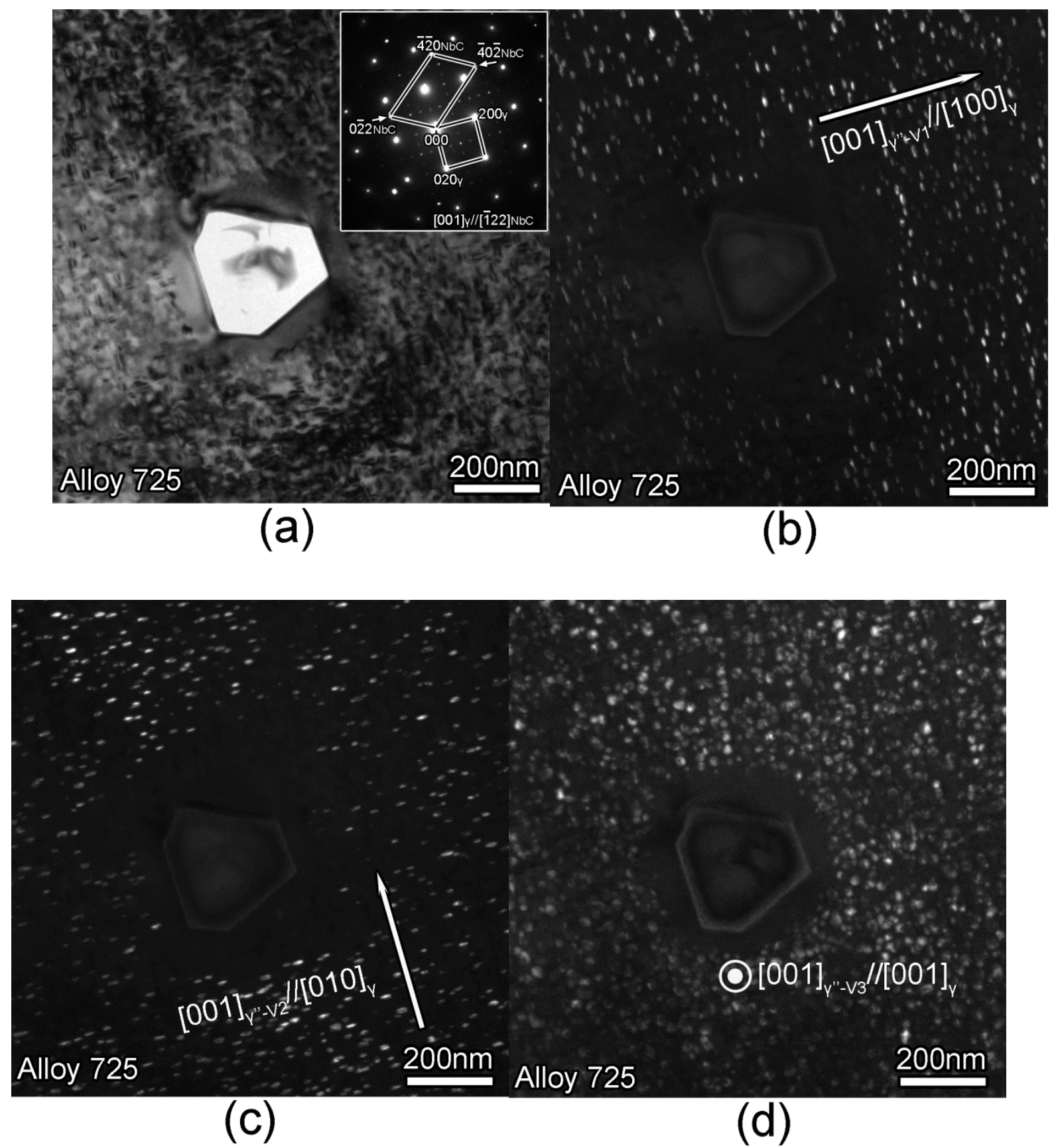

Fig.8 Variant dependent PFZ around a primary particle.(a) Bright field image and (b-d) dark field with three variant respectively.From the inserted diffraction pattern, some diffraction spots from the primary particlereflect the d-spacings of NbC crystal. 


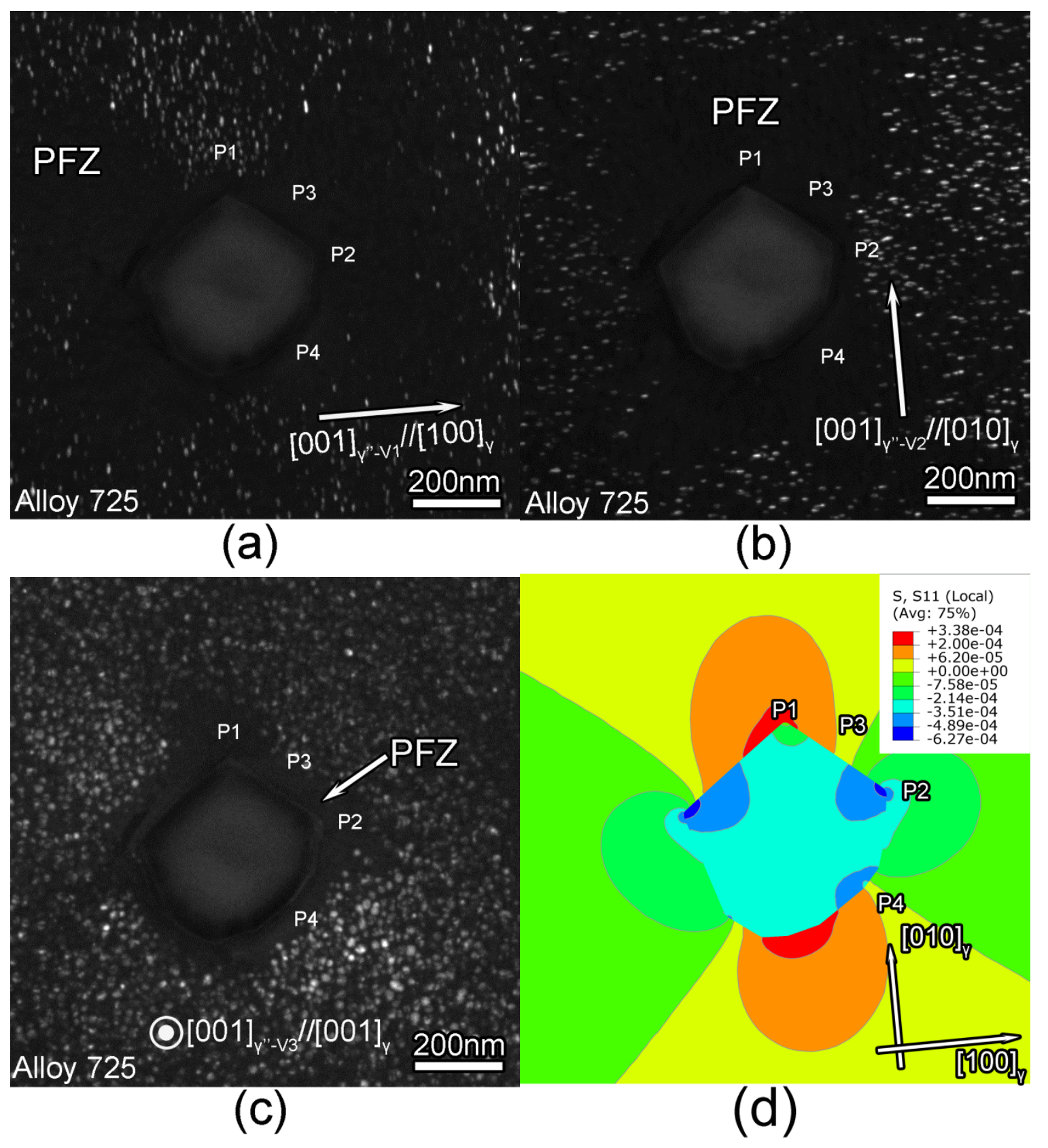



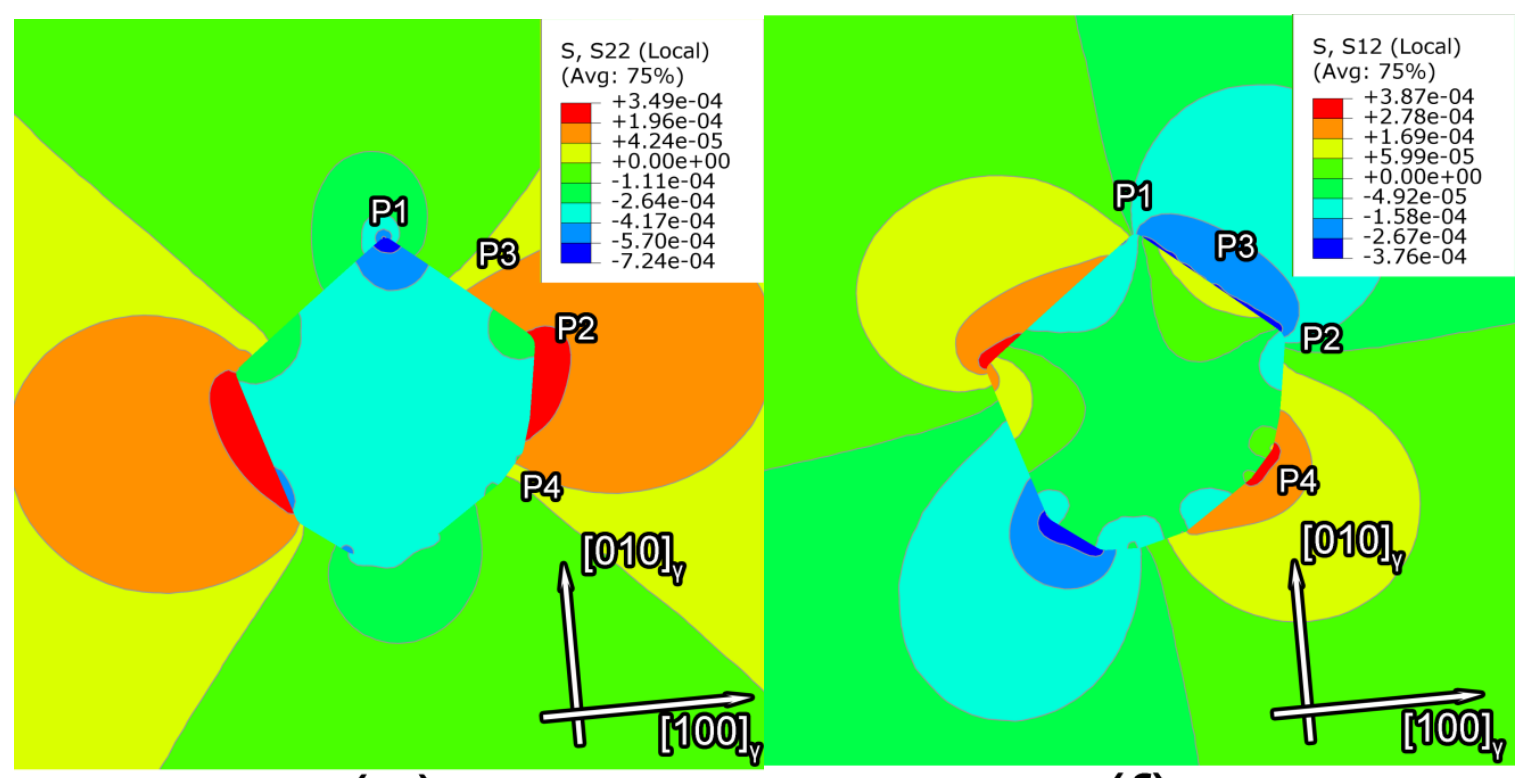

(e)
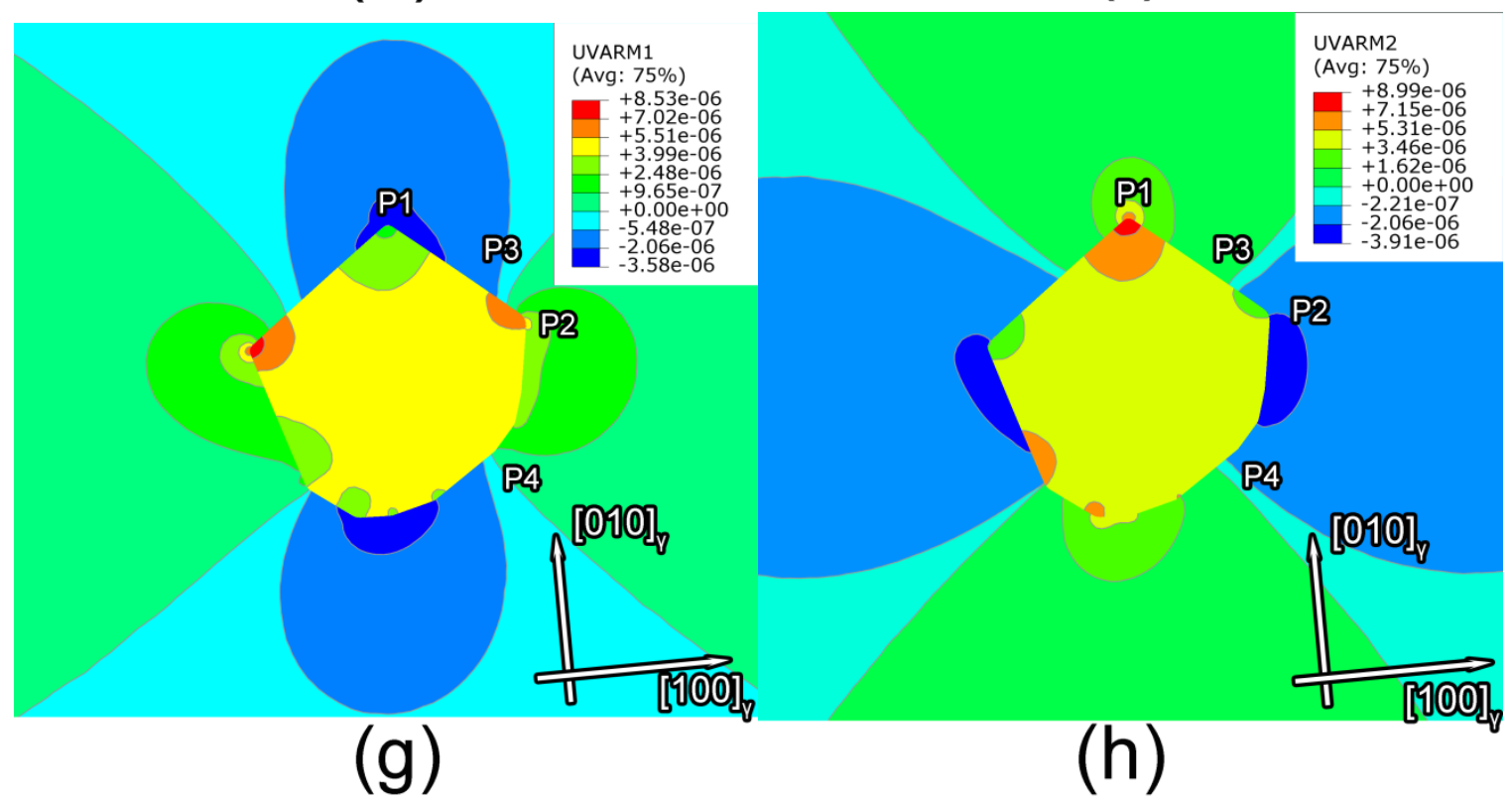

Fig.9Variant dependent PFZ around anirregular-shapedprimary particle (a-c) and stress field calculated by finite element method(d-f).Distribution of $\gamma^{\prime \prime}$ around primary particle for (a) variant 1, (b) variant 2, and (c) variant 3.(d) Stress distribution of $\sigma_{11}$. (e) Stress distribution of $\sigma_{22}$ (f) Shear stress $\sigma_{12}$ around the particle. (g) Specific interaction energy calculated for variant 1 , and (h) specific interaction energy calculated for varint 2. The blue colorrepresentsnegative (compressive) stress or negative interaction energy while the red represents positive (tensile) stress or positive interaction energy. The units of stress and energyare $10^{6} \mathrm{MPa}$ and $10^{6} \mathrm{MJ} / \mathrm{m}^{3}$, respectively. 


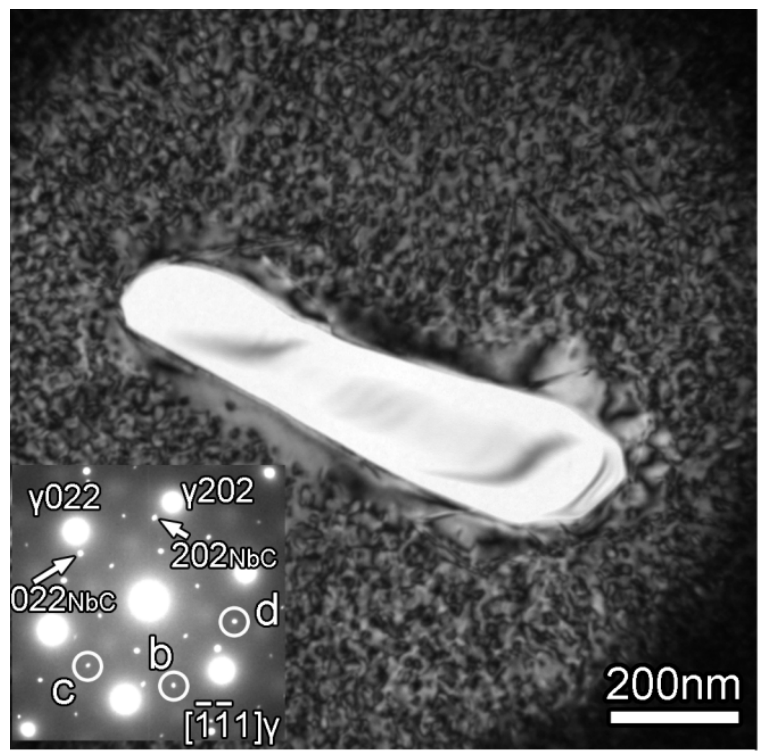

(a)

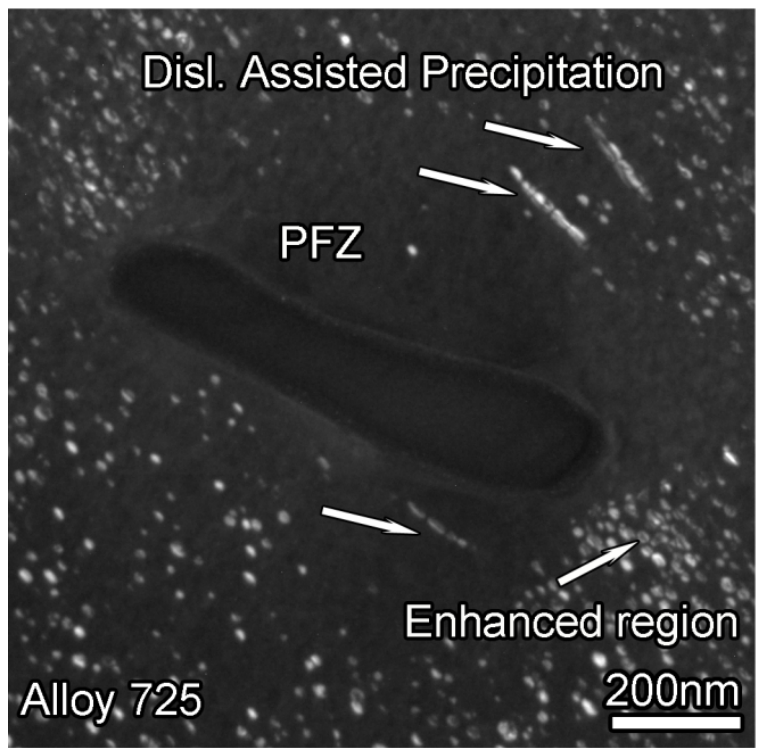

(c)

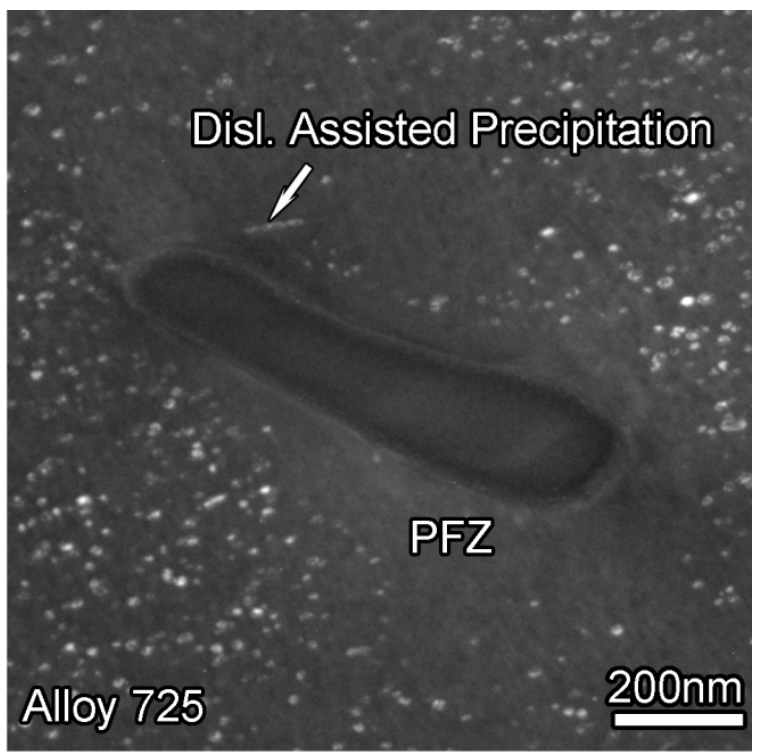

(b)

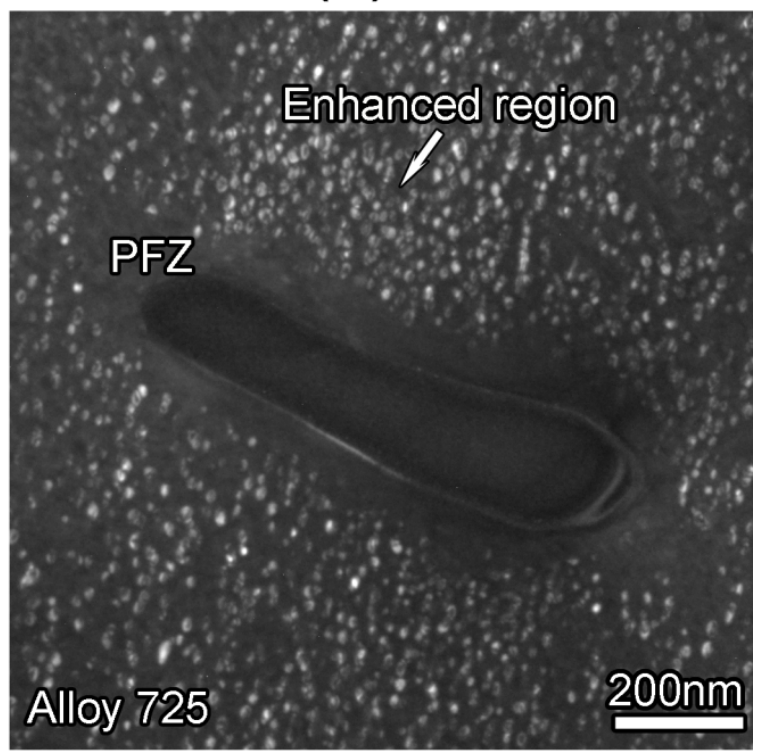

(d)

Fig.10 Variant dependent PFZ around a primary particle with zone axis [111] $\gamma$.(a) BF image of a primary particle with clear PFZ around it. (c-d)Variant dependent PFZ was observed in [-1-11] $\gamma$ zone axis. The morphology of three variants of $\gamma^{\prime \prime}$ phase is similar in this direction with a 60 degree rotation. However, a much complicated PFZ shape was developed due to the presence of primary particle. Dislocation assisted precipitation process was noted. 


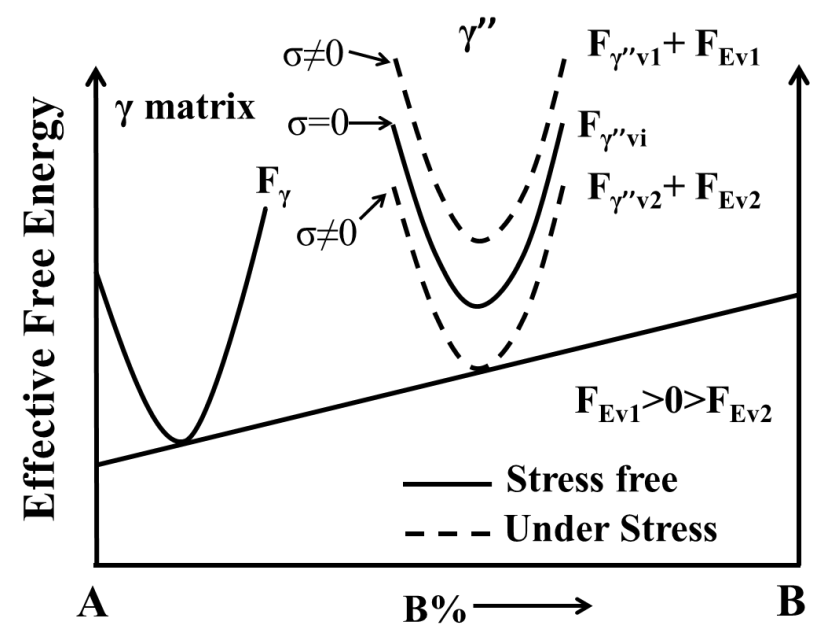

Fig.11 Schematic diagram showing the effect of elastic strain energy on the variant selectionprocess (the third variant is not plotted here). $F$, effective free energy; $F_{\mathrm{E}}$, elastic strain energy; vi, all the variant; $\sigma$, stress. 

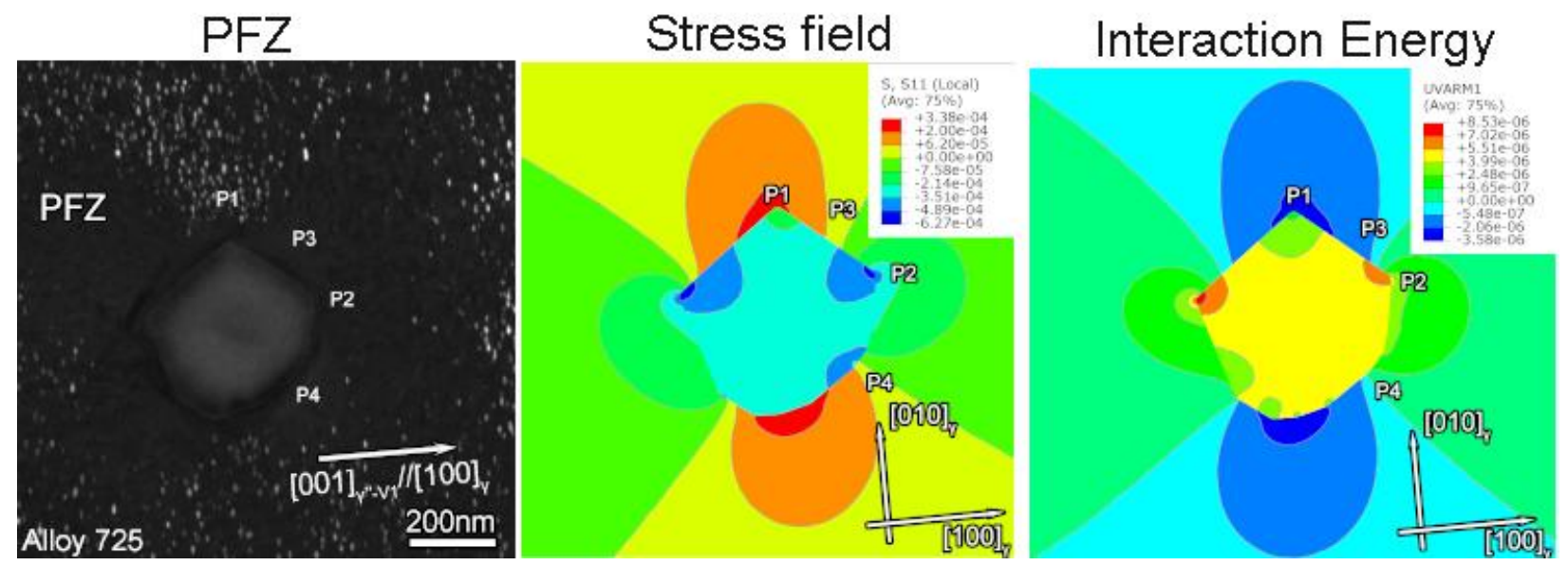